Geopolítica(s) Revista de estudios sobre espacio y poder ISSN: 2172-3958

\title{
Capitalismo y criminalización de la frontera en el circuito sacoleiro
}

\author{
Eric Gustavo Cardin (2015) A Expansão do Capital e as Dinâmicas das Fron- \\ teiras. Jundiaí: Paco Editorial, 235 pp. ISBN: 978-85-8148-831-8.
}

La obra presentada por Eric G. Cardin constituye la culminación de una prolongada labor de investigación sobre la relación entre la expansión de los mercados capitalistas y la resistencia ofrecida por el fenómeno del contrabando en la denominada Triple Frontera formada por Argentina, Brasil y Paraguay ${ }^{1}$. Su atención repara en el denominado circuito sacoleiro ${ }^{2}$ y la profundidad analítica de $A$ Expansão do Capital e as Dinâmicas das Fronteiras manifiesta el contenido político de la noción geográfica de frontera mediante un riguroso ejercicio de imaginación sociológica $^{3}$. Su objeto de estudio desvela la elasticidad de dicho concepto a través de la indagación de unas actividades comerciales transfronterizas desplazadas del marco legal y protagonizadas por una clase trabajadora enmarcada en un escenario económico sometido al progresivo crecimiento del flujo de capital desde hace aproximadamente cuatro décadas ${ }^{4}$.

El grueso de los trabajadores que desarrollan estas prácticas en la denominada Triple Frontera incurre en una serie de acciones comerciales ilegales. Esta circunstancia comporta un obstáculo añadido a la investigación cualitativa y explica, en cierta medida, el reducido número de individuos que deciden colaborar en la misma. No obstante, la muestra es sumamente representativa porque permite captar la heterogeneidad que compone el universo estudiado por el autor expresado por los múltiples roles funcionales (sacoleiros, piranhas, laranjas, etc.) que confluyen en las prácticas contrabandistas. Sus actividades coexisten con un mercado laboral

1 Un anticipo de sus resultados se pueden consultar en Eric Gustavo Cardin: "Trabalho e práticas de contrabando na frontera do Brasil com o Paraguai”, Geopolitica(s). Revista de estudios sobre espacio y poder, vol. 3, núm. 2, 2012, 207-234.

2 El término sacoleiro designa a los trabajadores encargados de la intermediación en las relaciones comerciales entre los empresarios que operan en Paraguay y los puntos de venta localizados en Brasil. Por consiguiente, esta figura es responsable de la distribución de muchos productos disponibles en el mercado paraguayo y su venta en los mercados brasileños.

3 El significado de esta idea procede del trabajo de Charles Wright Mills: The Sociological Imagination, Oxford, University Press, 1959.

4 Harvey contrapone esta etapa del ciclo económico capitalista a la fase dominada por las estrategias fordistas y sitúa dicha transformación en el contexto del derrumbamiento experimentado por el sistema de Bretton Woods, que propicia una transición hacia un modelo de acumulación flexible. Véase David Harvey: La condición de la posmodernidad. Investigación sobre los orígenes del cambio cultural, Buenos Aires, Amorrortu, 2012. 
ajustado a la legalidad y contribuyen, del mismo modo, al desarrollo regional como consecuencia del flujo migratorio provocado por la fuente de ingresos que supone para muchos hombres y mujeres (p. 39).

Las constantes reconfiguraciones observadas en la organización del llamado circuito sacoleiro responden a las políticas económicas aplicadas en la región, especialmente el proceso de desindustrialización, y sus efectos sociales. La apuesta del modelo económico descansa en la preferencia orientada a impulsar el sector terciario, en concreto la vertiente concentrada en el turismo, cuyos rasgos más significativos son la inestabilidad laboral y la mano de obra poco cualificada. De esta manera, la opción del contrabando emerge como una reacción a unas condiciones socioeconómicas muy particulares y asume unas connotaciones vinculadas a la supervivencia de sus participantes.

El peso de la opinión pública adquiere una fuerte relevancia en la interpretación sociológica del fenómeno y Cardin destaca la existencia de dos principales corrientes. En primer lugar, una línea interpretativa que condensa sus argumentos en las consecuencias atribuidas a las prácticas contrabandistas y su principal recurso reside en la criminalización de la población que habita la región para apelar a la aceptación de unos medios coercitivos con el propósito de normalizar unas acciones desmarcadas del control de las autoridades políticas -autores como Dreyfus, Naím o Abbott encarnan este posicionamiento ideológico-. Por el contrario, una segunda línea argumental concede un mayor protagonismo a las razones estructurales que conducen a los trabajadores del circuito sacoleiro a desplegar unas actividades ilegales motivadas por una atmósfera laboral definida por la incertidumbre y una pérdida sustantiva en los niveles de vida.

La expansión de los procesos de acumulación del capital en la región de la Triple Frontera está basada teóricamente en la controversia ilustrada por las perspectivas oficiales y extraoficiales porque, mientras las clases dirigentes avalan la importancia económica del sector turístico a través del apoyo estatal ${ }^{5}$ y la connivencia en la explotación de una fuerza de trabajo degradada (pp. 38-39), el circuito sacoleiro es condenado por los distintos gobiernos y demonizado por una amplia parcela de los medios de comunicación. Sin embargo, su existencia facilita el sustento de numerosos trabajadores y garantiza unos elevados ritmos en la circulación del capital. La principal acusación vertida sobre las actividades económicas implícitas consiste en asignar una fuerte influencia en el debilitamiento de la recaudación fiscal del Estado brasileño, e incluso adjudica su desarrollo a la presencia de grupos narcotraficantes y terroristas en la región (p. 140).

La aprobación de la Ley 11.898 expresa el triunfo de la corriente fiscalizadora, aunque el inicio de los debates parlamentarios en el año 2008 remite a la reflexión sobre las causas que alimentan el fenómeno contrabandista en la frontera. No obstante, la aplicación de políticas dirigidas a monitorizar las acciones vinculadas con el circuito sacoleiro no elimina los factores que proyectan el atractivo del mercado paraguayo, que mantiene una imagen relevante como fuente de ingresos y de su-

\footnotetext{
Cardin señala que el sector del turismo ha adquirido, en la última década, una importancia significativa en la economía mundial y representa una actividad esencial en los ingresos de un importante conjunto de países europeos y americanos. En el caso particular de Brasil, las actividades específicas del turismo contribuyen con un 3,6\% a la economía doméstica y 5,7 millones de personas ocupaban dicha rama productiva en el año 2006 (p. 32).
} 
pervivencia (p. 146). Las relaciones sociales están fuertemente mediatizadas por el Estado y sus correspondientes dispositivos, como recuerda Lefebvre, mediante la realización de marcos reguladores que buscan dificultar e imposibilitar las actividades de las clases menos favorecidas. Sin embargo, los testimonios aportados por algunos trabajadores evidencian la presencia de numerosas situaciones cotidianas que escapan al control estatal y posibilitan, por tanto, "el surgimiento de lagunas o brechas que son utilizadas como espacios de maniobra para el ejercicio de la libertad" (p. 147).

Esta capacidad de supervivencia favorecida por la flexibilidad de las fronteras para privilegiar la rápida circulación del capital durante el último tercio del siglo $\mathrm{XX}$ induce a desarrollar profundas reestructuraciones en las economías nacionales en la búsqueda de nuevos mercados, pero contrasta significativamente con las condiciones socioeconómicas de un amplio sector de la población. Una virtud del trabajo de Cardin reside en su capacidad para registrar el solapamiento de las diferentes escalas territoriales (municipal, regional, estatal, internacional) y sus lazos de dependencia, que devienen en numerosas contradicciones políticas y socioeconómicas, aunque en su análisis predomina una realidad dual integrada por una magnitud global y una dimensión local.

Esta caracterización de la coordenada espacial exige dotar a la idea de frontera de un significado abierto como resultado de los incesantes contactos detectados en dicha localización, pero su plasmación colisiona con los principios de soberanía territorial asignados a las funciones que ejercen las líneas fronterizas. No obstante, las continuas acomodaciones exigidas por el capital para ampliar sus márgenes de acción desdibujan las fronteras e introducen modificaciones en el paisaje social, como defiende Cardin. La máxima expresión de esta constante son las sucesivas transformaciones registradas en la organización del circuito sacoleiro o los estímulos de los diferentes gobiernos para imponer una disciplina en las prácticas laborales.

Las notables diferencias económicas y políticas existentes en la frontera generan numerosas formas de trabajo sustentadas, básicamente, por las desigualdades explícitas entre los países limítrofes. Esta peculiaridad explica el nacimiento de múltiples ocupaciones que persiguen aprovechar las posibilidades creadas, tanto legales como ilegales, por la situación de frontera (p. 50). El relieve de las actividades contrabandistas entre el municipio brasileño de Foz de Iguazú y la localidad paraguaya de Ciudad del Este reside en la importancia de las mercancías porque no configura únicamente un producto agregado que transmite un valor de cambio en el mercado de la Triple Frontera, sino que flexibiliza una red de interacciones tejidas por su circulación y esta fluidez permite la transformación de las fronteras (p. 67).

La porosidad de la frontera entre Brasil y Paraguay permite la constante reconstrucción histórica de la región sobre unos conflictos que transitan a través de unas acciones prácticas que suscitan unos discursos ideológicos divergentes. Cardin recurre a las trayectorias vitales de sus interlocutores para explorar las transformaciones del circuito sacoleiro porque, como bien indica el autor, "las modificaciones inscritas en la organización [...] reflejan los conflictos existentes en la frontera y las interpretaciones sobre las prácticas gubernamentales" (pp. 139-140).

Las imágenes cambiantes de la frontera de Brasil con Paraguay están asociadas a un dilatado conjunto de alteraciones intrínsecas a las políticas sociales y econó- 
micas adoptadas en la región (p. 191). Por consiguiente, la disputa por dominar el espacio es un producto que discurre en paralelo a otros procesos y en el caso brasileño esta pugna está determinada, entre otros motivos, por el proceso de democratización, la apertura económica que garantiza el desarrollo de nuevos acuerdos sociales, el fortalecimiento del sector terciario o la modernización de los parques productivos (pp. 191-192).

Los efectos coyunturales están acompañados de un distanciamiento en las fuerzas antagónicas estructurales. Esta asimetría facilita la constante expansión en los patrones de acumulación capitalista, puesto que la riqueza concentrada en los segmentos oligárquicos describe una tendencia inversamente proporcional a los procesos de exclusión experimentados por un sector significativo de la población. La lógica de esta ecuación adquiere visibilidad a través de la precariedad de los lugares que habitan los trabajadores que participan en las actividades informales, que engrosan el circuito como respuesta a su situación de vulnerabilidad social y económica. Al mismo tiempo, este fenómeno entronca con el surgimiento de áreas urbanas caracterizadas por la ausencia de unos niveles mínimos de salubridad y que coinciden con la proliferación de un desarrollo urbano exento de planificación ${ }^{6}$, mientras proporciona un contexto colmado de incertidumbre que sugiere la intervención política bajo el estéril argumento de la criminalización.

En estas circunstancias, los mecanismos de las estrategias políticas estatales pretenden suavizar las tensiones resultantes a través de la incorporación normalizada de los trabajadores inscritos en el circuito sacoleiro, aunque su resultado desemboca en la distorsión de los límites entre la legalidad y la ilegalidad (pp. 194195). Cardin reitera, precisamente, que la fragilidad de la acción legislativa radica en la superficialidad de sus medidas porque no profundiza en las causas que originan, entre otras razones, las prácticas sociales que se pretenden combatir. La Ley 11.898 capitaliza los esfuerzos gubernamentales para fiscalizar las actividades económicas etiquetadas de irregulares y que constituyen el funcionamiento del circuito sacoleiro. La conocida "ley de los sacoleiros" responde a los intentos por frenar las crecientes movilizaciones desencadenadas en la región del Puente de la Amistad y los constantes brotes de violencia en Foz de Iguazú (p. 181). Este escenario propicia una situación de emergencia que reclama una rápida intervención del Estado y, por tanto, el Gobierno brasileño fortalece la represión y aumenta los mecanismos de control con el propósito de eliminar los problemas de la región de las tres fronteras mediante la penalización. En cambio, sus estrategias no contemplan la posibilidad de sellar unos acuerdos estructurales que posibiliten a los trabajadores "una integración social más digna" (p. 178) y, en sintonía con Pinassi, la criminalización surge como "el intento de legitimar un conjunto de relaciones sociales históricamente desiguales" (p. 194).

El aumento de las inversiones y la progresiva intensidad de la fiscalización efectuada por los órganos del gobierno brasileño invitan a asegurar la recuperación de una parte del capital que sale del país ilegalmente mediante la adopción de tales acciones. Además, estas iniciativas suponen una mejora de las ventajas competitivas defendidas por la teoría económica liberal y formuladas por David Ricardo, ya que proporcionan unas condiciones beneficiosas para las empresas que actúan en el

6 Para una mayor información sobre este aspecto, véase Mike Davis: Planet of Slums, Londres, Verso, 2004. 
mercado nacional. Ahora bien, como subraya el propio Cardin, "el crecimiento de las convulsiones y el continuo aumento de la pérdida de divisas por parte del gobierno brasileño permiten afirmar que las inversiones realizadas no solucionan las dificultades estructurales que obligan a una parte de la población a vincularse con el circuito sacoleiro" (p. 177).

El fortalecimiento de las medidas coercitivas y represivas asociadas a las pautas de fiscalización pretende eliminar los problemas ocasionados por el contrabando localizado en la región de la Triple Frontera a través de la rigidez punitiva, pero no busca soluciones a largo plazo mediante la promoción de acuerdos estructurales que posibiliten "una integración social más digna de los trabajadores" (p. 178). En definitiva, Cardin reivindica resolver la conflictividad latente a partir de una triple estrategia constituida por "la construcción conjunta de políticas de intervención, la organización de espacios de diálogo común y el desarrollo de acciones coordinadas de diplomacia" (p. 65).

La construcción de la realidad subjetiva procedente de la experiencia de los trabajadores manifiesta las circunstancias conflictivas detectadas históricamente en el espacio regional del circuito sacoleiro. Las modificaciones contempladas en su organización no revelan simples adaptaciones o consecuencias ineludibles propiciadas por las políticas aduaneras, sino que expresan los conflictos registrados en la frontera y las múltiples interpretaciones generadas por las prácticas gubernamentales. En esta dirección, las políticas adoptadas por las instituciones brasileñas persiguen la resolución de un problema estructural desde la aplicación de medidas coercitivas violentas $\mathrm{y}$, por tanto, el resultado final es la perpetuación del carácter conflictivo.

La represión del circuito sacoleiro y la aprobación de una ley orientada a lograr un grado de disciplina en su funcionamiento fortalecen las barreras erigidas para controlar las prácticas sociales de los trabajadores, cuya respuesta consiste en la introducción de variaciones en sus repertorios estratégicos con la finalidad de "asegurar el mantenimiento del contrabando y la malversación" (p. 194). Además, la pervivencia de estas acciones resulta favorecida por las divergencias existentes en las políticas de los distintos países implicados y, de esta manera, "los flujos de personas y mercancías sufren intervenciones en función de las necesidades de los países vecinos" (p. 195).

La tesis sugerida en A Expansão do Capital e as Dinâmicas das Fronteiras certifica que el capital invade la totalidad de las estructuras que frenan su avance y esta dinámica deteriora unos modelos sociales opuestos a las exigencias del libre mercado, mientras proporciona un mayor grado de flexibilidad a las fronteras fiscales. Cardin logra explorar las discrepancias y las disyuntivas de la realidad del circuito sacoleiro mediante el contraste expresado por la información publicada por diversos medios de comunicación -tanto nacionales como internacionales-, los datos estadísticos procedentes de fuentes oficiales sobre el flujo comercial y el testimonio de los propios trabajadores que experimentan la frontera diariamente. Este ejercicio metodológico favorece la contextualización de la investigación y desvela el grado de relevancia que asume el tráfico de mercancías en la relación existente entre los municipios citados en el actual ciclo económico.

Por último, la lectura de este trabajo brinda una excelente oportunidad para reflexionar sobre la viabilidad social y política de un modelo económico que opta por 
la máxima flexibilidad de las fronteras para favorecer los márgenes de acción del capitalismo. Sin embargo, a pesar de la etiqueta de país emergente atribuida a Brasil por las principales instituciones mundiales en el terreno económico y financiero, esta apuesta desvela unas severas consecuencias provocadas por las exigentes condiciones de crecimiento traducidas en una mayor desigualdad social, una pérdida de ciertos derechos conquistados por la clase trabajadora y una mayor atmósfera de conflictividad determinada por unas políticas que persiguen suavizar el grado de fricción en el binomio capital-trabajo.

Mariano García de las Heras González Facultad de Ciencias Políticas y Sociología, Universidad Complutense de Madrid Email: mgarciadelasheras@gmail.com 